\title{
PEDAgogía, ALTERIdAd E INTERCULTURALIDAD EN AMÉRICA LATINA Y LOS PUEBLOS DEL SUR: ARGUMENTOS PARA RESPALDAR UNA INVESTIGACIÓN POSDOCTORAL
}

Claudia Vélez De La Calle Ph.D ${ }^{1}$

[...] Es necesario "deconstruir" lo pensado para pensar lo por pensar. Para desentrañar lo más entrañable de nuestros saberes y para dar curso a lo inédito, arriesgándonos a desbarrancar nuestras últimas certezas y a cuestionar el edificio de la ciencia. Enrique Leff (2007, citado en Walsh, C.)

\section{Preliminares}

Nuestras formas de vivir, relacionarnos, identificarnos y aprender han estado marcadas por las experiencias educativas hegemónicas de la modernidad y el modelo masivo de

1 Posdoctora en Educación, Ciencias Sociales e Interculturalidad, doctora en Educación, autora de numerosas obras, artículos y propuestas sobre el tema de la educación en diálogo con las pedagogías y epistemologías contemporáneas. Correo: cvelezoz@yahoo.es 
escuela que Occidente impuso a los países latinoamericanos que colonizó desde el siglo XV. Las representaciones, imágenes y discursos educativos intentan, en su proceso de formalización, lograr la intención de la igualdad; búsqueda afanosa por parecerse y modularse sobre los criterios de normalización donde reposan las validaciones de prestigio en las dimensiones personales, laborales, científicas, sociales y económicas.

Como el modelo del individuo (las técnicas del yo), la psicología clínica generó un relato teórico constituido en verdad en términos de posicionar la identidad racional (control de la persona) sobre un parámetro de cordura: salud mental integrada donde era posible dividir el consciente del inconsciente. La diferencia comportamental fue calificada de patología, perturbación o desviación, dependiendo del enfoque de análisis de turno.

Así las cosas, también desde la antropología de corte positivista y arqueológica la cultura diferente a la de Occidente era calificada como subordinada; su singularidad era subestimada. En segundo lugar, se hacía la comparación de dominio sobre la diversidad en términos clasificatorios civilización/barbarie, identificando de forma implícita la valoración peyorativa de lo que no es igual (léase mejor) a lo otro (Occidente).

El enfoque antropocéntrico excluyó las otras vidas no humanas como inferiores basado igualmente en el criterio racional: los seres humanos racionales y los no racionales; lógica dicotómica del A o no A propia de la racionalidad analítica (binaria) de la ciencia, la educación, la relación humana y sus procesos de socialización de más de cuatro siglos en Europa. La pedagogía general escolar (Herbart), huérfana muchos años de estatuto científico, fue pensada como un compendio didáctico de instrucciones para incorporar al sujeto al orden del disciplinamiento de la sociedad, la economía, la política, la ciencia y el poder.

Actualmente, las consecuencias de la aplicación de las polarizaciones civilización/ barbarie; episteme/doxa; yo/no-yo; antropocentrismo/teocentrismo; cordura/locura, se quiebran como horizonte de pensamiento único y los criterios fallidos de la universalidad se ven impugnados ante paradigmas como el de la complejidad y teorías/prácticas como las de la educación intercultural. La devastación del ambiente; la extinción de vidas humanas y no humanas; la eliminación biopolítica de pueblos enteros; el desencanto del progreso y la ilustración, y el imperio de la violencia física y simbólica en las sociedades actuales, interroga el modelo céntrico naturalizado y moralizado de las pedagogías escolares, sociales, especiales y, por supuesto, de las integraciones culturales forzadas.

Afortunadamente, la pluralidad como característica enriquecedora de la diversidad, se abre ahora para todas las dimensiones. La lógica del tercer excluido se pierde ante el tercero incluido; el reduccionismo científico y disciplinar reconoce la necesidad de reformar 
el pensamiento y la educación desde las perspectivas decolonizadoras. Las culturas bárbaras son ahora pensadas como culturas diferentes y particulares. La educación como práctica social entiende que hay estilos de aprendizaje, estilos de enseñanza, inteligencias múltiples; ahora la escuela abre sus fronteras espaciales, temporales, mediáticas en sus rutinas, rituales, escenarios y sujetos.

Finalmente, en la década de los 90 y en lo que va del siglo XXI se ha venido instalando en la región un pensamiento decolonialista que busca promover diálogos sur-sur y norte-sur de forma simétrica. Asimismo, busca impulsar un pensamiento y una práctica desde adentro de las representaciones de la región y las voces de los que han sido invisibilizados por el pensamiento y la acción colonial, en su tensión con lo moderno, tal y como lo expresa Mignolo:

\begin{abstract}
Desde que la modernidad es un proyecto, el proyecto triunfal del Occidente cristiano y secular, la colonialidad es, de un lado, lo que el proyecto de modernidad necesita eliminar y borrar en aras de implantarse a sí misma como modernidad y, del otro lado, es el sitio de enunciación donde la ceguera del proyecto moderno es revelado y, concomitantemente, es también el sitio desde donde los nuevos proyectos comienzan a desplegarse. En otras palabras, la colonialidad es el sitio de enunciación que revela y denuncia la ceguera de la narrativa de la modernidad desde la perspectiva de la modernidad misma, y es al mismo tiempo la plataforma de la pluriversalidad, de proyectos diversos provenientes de la experiencia de historias locales tocadas por la expansión occidental (como el Foro Social Mundial demuestra); así la colonialidad no es un nuevo universal abstracto (el marxismo está incrustado en la modernidad (citado en Escobar, 2003, p. 62).
\end{abstract}

Con base en lo anteriormente descrito, este artículo pretende dar cuenta de un nuevo horizonte de sentido en la educación intercultural, narrada y dibujada desde los asombros y la estética que lo no hegemónico genera. Apoyada en las teorías de Frantz Fanon (1983) Boaventura de Sousa Santos (2010), E. Dussel (1.976), Mignolo (2007), Quijano (2007), Catherine Walsh (2005) y otros sobre la necesidad de decolonizar el pensamiento del Sur y abrirse a nuevas ecologías de los saberes (comprendiendo el Sur como las voces silenciadas de los sujetos, pueblos, saberes ocultados por las acciones de los colonizadores y los grupos dominantes), se intentará dar cuenta, desde los relatos argumentativos, de cómo la diferencia deja de ser un horror o una práctica subjetiva divisoria para pasar a ser interpretada, en el contexto pedagógico, como la alteridad inalienable. Para ello el presente texto contará con la siguiente ruta de sentido: 
- Pensamiento e identidades pedagógicas propias : una tarea por sistematizar.

- La pedagogía moderna, supervivencia del dominio colonial en saberes y sujetos educativos.

- La concepción del sujeto pedagógico y la colonialidad del ser.

\section{Primer puerto \\ Pensamiento e identidades pedagógicas propias: una tarea por sistematizar}

Las expediciones pedagógicas realizadas en Colombia, Venezuela, Argentina y México, en la primera década del siglo XXI han dado respuestas múltiples al interrogante ¿Cómo enseñamos/aprendemos/relacionamos en las prácticas educativas escolares/sociales/ diferenciales en el Sur?

Otra de las vías desde las que se ha intentado responder este interrogante es desde las investigaciones arrojadas por el grupo de Historias de las Prácticas Pedagógicas y desde la forma como en América Latina se han adaptado y adoptado las teorías educativas de la Conquista a nuestra época. Afortunadamente, en Colombia y la región el inventario de producción de saber ha sido extenso en estos 34 años de existencia del grupo reconocido con este nombre.

Prácticas pedagógicas alternativas como las derivadas del Movimiento Pedagógico Nacional (l982), de las redes pedagógicas (l996) y de las Innovaciones educativas (l99o), también hicieron sus acercamientos y pudieron describir y conceptualizar sobre el docente como sujeto de saber; la necesidad de comprender los contextos culturales de la escuela como modos de producción de sujetos pedagógicos, prácticas y saberes. Otros países ensayaron las réplicas y dejaron evidencias sistemáticas de sus hallazgos. Pero la tarea es inicial porque falta socializar más estos resultados para dar cuenta de cómo nos relacionamos pluralmente entre nosotros, con el saber, con el pensamiento, y cómo orientamos aquello que sabemos hacia la transformación de nuestra realidad socioeducativa y política.

Sin embargo, la historia educativa lineal y oficial ha estado contada, para la gran mayoría, desde el orden del conocimiento en las investigaciones historiográficas y lo que se trata de objetar es que ese orden no es universal, por ello desde allí no se puede definir una pedagogía única para todas las regiones. Como dice Catherine Walsh $(2005,28)$ «la historia del conocimiento está marcada geohistóricamente, geopolíticamente, y geoculturalmente; 
tiene valor, color y lugar de “origen” y agrega Escobar $(2003,62)$ « ¿Existe una necesidad lógica para creer que el orden tan esquemáticamente caracterizado arriba es el único capaz de devenir global?».

Así las cosas, existen varias formas de contar la historia colonial de la educación y la pedagogía en Colombia y América Latina que deben ser revisadas y en lo posible socializadas, para conocer nuestras propias representaciones de saber sobre las experiencias educativas de varias décadas.

En esta línea, cabe mencionar el aporte de Barbosa (2011):

El marco de una historia de la educación latinoamericana significó una generalización de sus procesos educativos y una descontextualización de los sujetos partícipes del conjunto de experiencias educativas en curso en la región. Una consecuencia derivada es la narrativa aplanada de la educación, desarticulándola de otros contextos educativos contemporáneos y volviendo invisibles las diferencias existentes por medio de una imposición de parámetros con fuerte tendencia homogeneizadora, expresados muy substancialmente en la difusión simbólica e ideológica del conjunto de valores convenientes a la manutención de la dominación. El descubrimiento del "otro" (Todorov, 2003) y, a la vez, su inmediata negación desde los parámetros culturales y políticos incluyendo los procesos educativos - provocó una particularidad en la conformación de una identidad latinoamericana: la configuración de un tipo de vínculo dependiente en las múltiples dimensiones de la vida político-económica, social y cultural. En este sentido, es válido pensar las implicaciones de la ausencia de la "otredad" en nuestros referentes formativos. Más que apalancar una estructura geopolítica de dominación hegemónica del norte hacía el sur, silenciosamente se fue acomodando un dominio mucho más peligroso: el dominio del saber, del conocimiento, de las ideas y sus formas de representación simbólica. (7)

Teniendo en cuenta las palabras de Barbosa, se podría reiterar como intención que la tarea está incompleta porque su visión (la de la pedagogía y la historia colonial de la educación) ha sido parcializada e invisibilizada por las políticas socioeducativas, las cuales han impuesto la mercantilización y privatización de la educación desde los años ochenta en América Latina. Arriesgando intuiciones previas, propuestas como supuestos a investigar, se podría advertir que: 
1. Históricamente en América Latina hay rasgos que permiten suponer la construcción, como hecho social, de un Pensamiento Pedagógico Latinoamericano (PPL) vinculado a los contextos socioculturales y a la tarea política de emancipar a los grupos más vulnerables de su condición de marginación, analfabetismo y enajenamiento. Lo anterior derivado de los saberes y acciones que la Teoría de la Liberación, orientada por varios educadores populares, demarcó:

El final del siglo XVIII, caracterizado por la insurgencia revolucionaria en América Latina y por conflictivos procesos de reordenamiento de lo social, de lo político y de lo económico, constituyó en el hito fundacional, por así decir, del nacimiento de la ilustración latinoamericana y de las primeras propuestas de elaboración de un proyecto educativo responsable por concebir una nueva cultura política calcada en la participación popular y dirigida a la emancipación política de la región. Su perspectiva se inscribía en la aportación de un papel político a la educación en la construcción y fortalecimiento de lo social como parte constitutiva de los cambios coyunturales previstos para este momento de la historia de Latinoamérica (Barbosa, 2011, p. 8).

2. Existen actores en la región, pertenecientes a varias disciplinas o roles, que desde los movimientos de independencia a la fecha preconizaron discursos motivados hacia la liberación política, especialmente reconociendo que la educación juega un papel importante en estos procesos de transformación y cambio. Simón Rodríguez (Venezuela), José Martí (Cuba), Paulo Freire (Brasil), Gabriela Mistral (Chile), Santiago Castro-Gómez (Colombia), Frantz Fanon (Martinica), Eduardo Galeano (Uruguay), Manuel Zapata Olivella (Colombia), Catherine Walsh (Ecuador) y Eduardo Lander (Venezuela), son algunos de ellos; en las últimas décadas se han unido a la causa otros autores como Abraham Magendzo, Boaventura de Sousa Santos, E. Dussel, Antonio Elizalde y demás pensadores de la pedagogía crítica y del pensamiento decolonizador. A este enfoque pertenecen también los que opinan que las formas y modos diversos de hacer educación en América Latina pueden dar cuenta de diferencias substanciales con las que orientan enfoques pedagógicos y didácticos, socializados en la teoría educativa desde la década de los setenta en la región y repetidos por las facultades de educación.

3. Las prácticas socioeducativas presentes entre los pueblos mestizos, afrodescendientes, indígenas, campesinos y urbanos, de todos los países latinoamericanos, muestran que el hecho intersubjetivo de relación es inter y transcultural, es decir, coexisten y hay 
flujos comunicacionales en grupos diversos que desafían la educación hegemónica, donde la excepción se sitúa en la pretensión masiva de sumar sujetos sobre un mismo modelo. Por ello, lo que nos integra es la diferencia, el asombro por el otro y no el estigma del otro. Esta interculturalidad obliga a transformar el canon de la pedagogía y de la educación en todas sus acepciones y categorías clásicas de organización de la enseñanza y de los saberes: currículos, didácticas, prácticas evaluativas, tal y como lo nombra Walsh:

Además de ser principio ideológico y organizador, la interculturalidad construye un imaginario distinto de sociedad, permitiendo pensar y crear las condiciones para un poder social distinto, como también una condición diferente, tanto del conocimiento como de existencia, apuntando a la descolonialidad (2005, p. 31).

4. Finalmente, la pedagogía, sin resolver unívocamente su estatuto conceptual, contiene múltiples saberes, imaginarios y representaciones que vinculan a los sujetos y actores educativos con sus formas de aprehender y apropiar los aprendizajes. Los modos de producción y significación de esos aprendizajes configuran sujetos distintos a los europeos, norteamericanos y de otras latitudes. Supuestos como que la pedagogía y la educación determinan la cultura y no viceversa (la cultura antecede a las prácticas educativas), deben ser replanteados para el caso Sur.

De la misma forma, afiliaciones como el afecto, la creatividad y las analógicas de pensamiento, factores clave en la producción de saber que se habían anatematizado como modos irracionales, tribales y des-ordenados de conocer, constituyen rasgos de las escenas educativas en América Latina que, con las expresiones artísticas, deben evidenciarse en su carácter y condicionamiento potente del enseñar/aprender.

La resignificación de connotaciones y categorías de análisis como: escuela, sujeto que sabe, sujeto que desea saber, contenidos de enseñanza/aprendizaje y validaciones de lo aprehendido, se dan y circulan distinto en los contextos locales, urbanos y rurales de América Latina. Describirlos y socializarlos potenciaría los cambios que las prácticas pedagógicas fallidas de la escuela tradicional, masiva y hegemónica requieren.

Todo ello necesario para fundamentar la alternatividad y la resistencia educativa, especialmente ahora que las políticas y prácticas de la gestión de la calidad empresarial se desarrollan agresivamente en todos los escenarios, experiencias y discursos educativos, desplazando la reflexión de lo propio pedagógico al olvido para integrar forzosamente y 
hegemonizar de nuevo lo que siempre ha sido subordinado: la diferencia cultural, social, subjetiva y epistémica de nuestras culturas.

\section{Segundo puerto \\ La pedagogía moderna, supervivencia del dominio colonial en los saberes y los sujetos educativos}

Nuestra mentalidad, experiencia educativa y cultural han configurado nuestra subjetividad y colonizado la percepción que tenemos de lo propio y de lo otro. Aunque no es novedoso nombrarlo, en los escenarios académicos, intelectuales y sociales, donde actúan educativamente generaciones diversas, se ha vuelto lugar común y compartido la crítica al desarrollismo; la desigualdad; la asimetría de razas, pueblos, disciplinas y conceptos, y la jerarquización de roles y ciencias. Pese a ello, las prácticas de enseñanza/aprendizaje/ relacionamiento no varían de su escena clásica de transmitir y dominar a los estudiantes en un discurso omnipresente y ubicuo en que el estudiante (el colonizado) no existe sino como espejo de lo que el docente quiere imponer en su discurso.

De otro lado, el estudiante asiste y consiente participar pasivamente (valga la paradoja) del simulacro de creer que existe, su palabra, para un docente narcisista, autista repetidor de textos ilustrados que se aprenden por efecto mágico en la cátedra universitaria. Como lo diría Baudrillard, todos consienten (consentimos) en que el simulacro siga pero sabemos profundamente que ni las epistemes de los docentes, ni los saberes de los estudiantes, establecen el diálogo pedagógico necesario para encontrarse y ninguno de ellos supera el nivel del monólogo personal.

Se aprenden las representaciones de la relación amo-esclavo que la colonización del poder ha replicado en las esferas económicas/políticas y científicas. Esta hiancia entre docentes y estudiantes queda congelada en el tiempo y, aunque estéril, sirve a los propósitos de perpetuación del statu quo del sistema educativo simulando y/o sustituyendo el conocimiento (que ya nadie posee) por una jerga profesional cantinflesca. 
En el vacío de saber, igualmente es recurrente notar el vacío del otro. Mientras el docente habla (bajo el espejismo de ser escuchado y comprehendido), el estudiante se refugia en los ordenadores personales, las redes sociales o la conversación ocasional con el compañero, pues hace rato ha aceptado que la regla del juego es parecer que se está aunque no se esté; desaparecer y hacerse el muerto para que el docente florezca.

¿Por qué, aunque se reconozcan las importancias de las llamadas pedagogías activas, sociales, participativas y culturales, la escena sigue congelada en el tiempo? Una de las respuestas puede ser que la obediencia cultural, política y social apropiada, cual impronta de la dominación y las dictaduras del disciplinamiento familiar, escolar y social, ha creado un cuerpo casi material del silencio y la aceptación del amo absoluto, difícil de retar, ya que el castigo para el disidente es la eliminación.

Lamentablemente para la estima de la profesión, docentes y directivos educativos aparecen comúnmente como los sujetos sostenedores y reproductores del orden del sometimiento, transmitiendo fácilmente la sujeción y castigando la subordinación con la expulsión del sistema educativo. Esta práctica educativa, heredada de los comportamientos coloniales, está instalada tanto en los espacios burocráticos como en las aulas escolares (día tras día) de nuestra ya larga memoria de dominación. El desencanto obliga a buscar otras fuentes.

La consulta interdisciplinar valida la obediencia como un excelente trabajo de normalización. La psicología en su papel de sacerdocio moderno avala los sujetos obedientes; en este mismo sentido, el mundo organizacional y laboral requiere el grupo de personas que aceptan el rol de forma incondicional. Nuevamente la desobediencia molesta, es mal vista y no es aprobada en la rutina de lo políticamente correcto.

Cuando se consulta la noción de decolonialidad, tanto en los trabajos de Quijano (2001) como en los de Immanuel Wallerstein (2000), es claro que la pedagogía, en la jerarquización que de ella hizo la modernidad, terminó siendo un saber menor, que enseña a los sujetos educativos a subordinarse. Si bien es cierto que la división internacional del trabajo se dio entre centros y periferias, las ciencias copiaron el paradigma. Igualmente, así como la jerarquización étnica- racial de las poblaciones dominó a los negros, indígenas del Sur ante los blancos del Norte, los docentes hicieron lo mismo con los estudiantes. Es decir, en las teorías pedagógicas modernas y contemporáneas no ha habido transformación sino adaptación de las formas de dominio del colonialismo moderno a colonialidad global. 


\title{
III. Tercer puerto \\ La concepción de sujeto pedagógico y la colonialidad del ser
}

\begin{abstract}
Foucault situó las sociedades disciplinarias en los siglos XVIII y XIX; estas sociedades alcanzan su apogeo a principios del XX, y proceden a la organización de los grandes espacios de encierro... Pero lo que Foucault también sabía era la brevedad del modelo: sucedía a las sociedades de soberanía, cuyo objetivo y funciones eran muy otros (recaudar más que organizar la producción, decidir la muerte más que administrar la vida); la transición se hizo progresivamente (Deleuze, 1991).
\end{abstract}

Estudiar la identidad de un sujeto pedagógico, en escenarios educativos diversos e interculturales, que tiende a constituirse múltiplemente en el tránsito de una sociedad disciplinar hacia otra de la sociedad del control, parece tentador. Foucault era profético en anunciar la finalización de las sociedades disciplinares y el advenimiento de las sociedades del control, con metáforas nuevas del simulacro de la libertad democrática, afectando la constitución de dividuos replicados en serie según los mandatos del mercado. A esta profecía se adicionó la de vislumbrar en Deleuze (1991) su papel como filósofo de este tipo de sociedades contemporáneas.

En este caso, la lectura de Gilles Deleuze retomaría como antecedente los aportes teóricos de M. Foucault (1976) a la comprensión de cómo la sociedad disciplinar viene transformando sus signos de disciplinamiento corporal, científico y social de las instituciones de vigilar y castigar (incluyendo la escuela en ellas) para la actual sociedad del conocimiento. Es recomendable leer a Deleuze (1925-1995) en el concepto de diferencia subjetiva para reconocer que el autor centra la diferencia entre sery sujeto como un proceso en deconstrucción conceptual alrededor de categorías complejas como el de la identidad; contrastando con Habermas:

De nuestra identidad hablamos siempre que decimos quiénes somos y quiénes queremos ser. Y en esa razón que damos de nosotros se entretejen elementos descriptivos y elementos evaluativos. La forma que hemos cobrado merced a nuestra biografía, a la historia de nuestro medio, de nuestro pueblo, no puede separarse en la descripción de nuestra propia identidad de la imagen que de nosotros nos ofrecemos a nosotros mismos y ofrecemos a los demás y conforme a la que queremos ser enjuiciados, considerados y reconocidos por los demás (Habermas, 1993, p. 115). 
Deleuze (1991) muestra que lo que aparece tras la subjetividad no es la antigua noción de ser trascendental, sino la diferencia; el ser como diferencia posibilita pensar este aspecto en los escenarios educativos del enfoque de la educación intercultural. Lo anterior derivaría en la necesaria fundamentación filosófica de la pluralidad en el pensamiento pedagógico y en la práctica educativa diferencial, no solamente para las modalidades de educación especial ni la escolar, sino para todo tipo de proceso de formación y diálogo transcultural.

Realidades como el mercado y el poder del consumo han producido dividuos y eliminados, los sujetos que no están en capacidad de estar involucrados en la compulsión de adquirir la cultura hegemónica, entre otros que el capitalismo transnacional pretende.

En consecuencia, la comprensión del sujeto de la educación en esta contemporaneidad implica que «los individuos han devenido "dividuales" y las masas se han convertido en indicadores, datos, mercados o "bancos"» (Deleuze, 1996, p. 256), frente a esto Guattari (2004) sostiene que:

\begin{abstract}
El capitalismo se apodera de los seres humanos desde su interior. Su alienación por medio de imágenes e ideas no es más que un aspecto de un sistema general de sometimiento de sus modos fundamentales de semiotización, tanto individual como colectivo. Los individuos están «equipados» con modos de percepción o de normalización del deseo al mismo título que las fábricas, las escuelas, los territorios(...). El capitalismo pretende apoderarse de las cargas de deseo producidas por la especie humana. Se instala en el corazón de los individuos a través del cauce indirecto de la servidumbre maquínica (Guattari, 2004, pp. 95-96).
\end{abstract}

Mientras el mercado pretende una igualdad de condiciones de acceso, pensar el sujeto de la educación en contextos de la interculturalidad, por el contrario, aboca la reflexión a considerar la posibilidad de existencia simbólica de que los sujetos son asimétricos, de que no todos enuncian su condición porque han sido silenciados por las prácticas educativas de la obediencia, el sometimiento y la subordinación de los seres y los saberes a otro superior, construido por los procesos históricos de dominación y colonización.

El sujeto de la condición ética está siendo amenazado por la sociedad del consumo y por el proyecto narcisístico individual donde con la adquisición del poder económico pareciera que todo es posible de obtener. Trabajar y conquistar de forma fácil el éxito prometido por la publicidad y los medios, opaca al sujeto existencial y explícita como modelo (inclusive 
para la tarea de formar docentes) el animal laborans (Campillo 2004), dinámico, ubicuo y depredador de los demás quienes se constituyen en obstáculo para su triunfo individual.

\begin{abstract}
En la sociedad de consumidores nadie puede convertirse en sujeto sin antes convertirse en producto, y nadie puede preservar su carácter de sujeto si no se ocupa de resucitar, revivir y realimentar a perpetuidad en sí mismo las cualidades y habilidades que se exigen en todo producto de consumo. La "subjetividad" del "sujeto", o sea su carácter de tal y todo aquello que esa subjetividad le permite lograr, está abocada plenamente a la interminable tarea de ser y seguir siendo artículo vendible. La característica más prominente de la sociedad de consumidores es su capacidad de transformar a los consumidores en productos consumibles (Bauman Z., 2004, pp. 25-26).
\end{abstract}

El vacío de la ética en el sujeto es el vacío producido por el capitalismo extendido y las formas de negación subjetiva del mercado. Según Baudrillard:

Libre para ser uno "mismo" significa en realidad: libre de proyectar sus deseos en bienes de producción. "Libre para disfrutar plenamente la vida..." significa: libre para ser irracional y regresivo y, de tal modo, adaptarse a un determinado orden social de producción (1978, p. 211).

Lo intercultural en educación implica delimitar desde la conceptualización (y en correspondencia con la observación simulada de lo real) quién es el otro: «La alteridad radical es a la vez inencontrable e irreductible. Inencontrable como alteridad en sí (evidentemente un sueño), pero irreductible como regla del juego simbólico, como regla del juego del mundo» (Baudrillard, 1991).

La colonialidad del poder, del saber y del ser se interrelacionan para producir una mirada de la ciencia desde la resignificación de nuevos sentidos y lenguajes:

La ciencia (conocimiento y sabiduría) no puede separarse del lenguaje; los lenguajes no son sólo fenómenos "culturales" en los que la gente encuentra su "identidad"; estos son también el lugar donde el conocimiento está inscrito. Y si los lenguajes no son cosas que los seres humanos tienen, sino algo que estos son, la colonialidad del poder y del saber engendra, pues, la colonialidad del ser. (Mignolo, 2003, p. 669) 
Sobre los sujetos que constituyen a los docentes/estudiantes que son formados en las facultades de educación, se tiene que las relaciones de género, generación y afiliaciones familiares han sido modificadas en cuanto los horizontes éticos de la modernidad. Los valores de construcción del sujeto moral de la ilustración no son los de la sociedad de la información; el conocimiento y el capitalismo cognitivo que circunda producen, en consecuencia, el autismo de los programadores de currículos de la formación de maestros que así lo demuestran; estos desconocen la incidencia del contexto en otras formas pertinentes de enseñar la pedagogía y la actualizan sustituyendo el saber por la mediación.

En la academia actual, el principio de despersonalización del saber ha resquebrajado la condición que anudaba el lazo docente/estudiante. El conocimiento no tiene los atributos sustantivos de antes sino que se presenta y representa como un producto comercial con valor de intercambio. «Cuánto más produzcas escritura codificada, más sabes», parece ser la ecuación pedagógica de la actualidad. El ser del maestro de este siglo es un ser intelectualizado, naturalizado científicamente pero con pocas habilidades solidarias y subjetivas para reconocer las necesidades del contexto al que pertenece y para construir otras racionalidades internas en su personalidad.

Esta condición es la que obliga a que muchas facultades de educación piensen el lugar de la subjetividad de los estudiantes que ingresan, asimismo, obliga a considerar incluir en sus propuestas de formación didácticas sustantivas donde cabe la posibilidad de expresión personal de los docentes que allí se forman. La dificultad en estas propuestas es que en algunas ocasiones queda expulsado de la escena de formación el conocimiento (el cual también es importante) y la alteridad.

Dicho de otro modo, la carencia de visibilidad del otro, que la exacerbación del individualismo ha causado, puede ser neutralizada en la formación de docentes con un alto contenido de educación intercultural y de diversidad, donde quede claro que las relaciones intersubjetivas no son hegemónicas sino plurales. La diferencia no es enfermedad ni es jerarquizable. El otro diverso enriquece el paisaje pedagógico con sus diferentes imaginarios y percepciones. Aquello que se ha expuesto como lo feo, lo detestable y ocultable constituye realmente el deseo de saber de lo humano sobre lo vital.

Para contrarrestar la invisibilidad del otro, la consideración sobre la identidad del docente, tanto subjetiva como profesional y social, sigue siendo importante. El llamado a instalar de nuevo el proyecto colectivo en sintonía con el proyecto individual es una perspectiva que posibilitaría la formación de docentes con sentido social e intercultural del futuro. Muchos estudiantes carecen de sentido de pertenencia y participación a un 
grupo determinado. Sus filiaciones son pocas o desconocidas, bien porque han sido educados como hijos únicos o porque son criados por familias sustitutas o madres/padres divorciados. La crisis de los cuidadores ha fortalecido la soledad humana a temprana edad.

Somos creadores de una sociedad educativa y académica del horror, porque todo es igual, lineal, cartesiano, ordenado monolíticamente. Esa cultura de la cuadrícula, de la copia seriada, de la norma estética publicitada, del eje x/y, estalla por su aburrida estandarización. Las bellezas fabricadas iguales, como modas, imploran por el contraste. Las narrativas científicas codificadas por APA versión 6.o revientan el relato potente de un saber que va más allá de los criterios de validación científica.

La inter y transculturalidad es una invitación a transgredir el control de las sociedades contemporáneas; por ello las escenas pedagógicas deben atreverse a romper con su escena performativa de la obediencia a la rigidez disciplinar, metódica, investigativa, y escuchar con agrado el discurso de defensa por la diferencia.

Si alguna vez fue urgente el elogio a la dificultad que Estanislao Zuleta proponía, hoy más que nunca se impone la búsqueda por el mosaico plural que el color de la deconstrucción epistémica/pedagógica insinúa.

\section{Referencias}

Baudrillard, J. (1978). Cultura y Simulacro. Barcelona: Editorial Kairos.

Baudrillard, J. (1991). La transparencia del mal. Ensayo sobre los fenómenos extremos. Barcelona, España: Anagrama.

Bauman, Z. (2004). Modernidad líquida. Argentina: Fondo de Cultura Económica de Argentina.

Barbosa, L. (2011). Pensamiento pedagógico latinoamericano, educación libertaria y pedagogías alternativas. El fortalecimiento del poder popular. 9 p. Tomado de https://zur2.wordpress. com/2011/o8/o4/pensamiento-pedagogico-latinoamericano-educacion-libertaria-y-pedagogiasalternativas-en-el-fortalecimiento-del-poder-popular/. Consultado en marzo 5 de 2015.

Campillo, N (febrero, 2004). Hannah Arendt, técnica y política“La tecnología como un desarrollo biológico de la humanidad" Departamento de Filosofía, Institut Universitari d'Estudis de la Dona, Universitat de València. Recuperado de http://metode.cat/es/Revistas/Articulo/HannahArendt-tecnica-i-politica. Damiani, L., Bolívar, O. (Comp.). (2007). Pensamiento Pedagógico Emancipador latinoamericano. (Por una Universidad Popular y Socialista de la Revolución Venezolana) Caracas: Imprenta UBV. 
De Sousa Santos, B. (2010). Decolonizar el saber, reinventar el poder. Ediciones Trilce- Extensiòn Universitaria. Universidad de la Repùblica. Montevideo, Uruguay.

Deleuze, G. (l991). Posdata sobre las sociedades del control. En Ferrer, C. (Comp). El Lenguaje Literario. Montevideo: Editorial Nordan.

Dussel. E. (1992). 1492. El encubrimiento del otro. Origen del mito de la modernidad. Madrid, Nueva Utopia, 1992.

Escobar, R. (enero-diciembre, 2003). Proyecto latino / Latinoamericano modernidad/colonialidad. En Mundos y conocimientos de otro modo. El programa de investigación de modernidad/ colonialidad latinoamericano. Revista Tabula Rasa, 1, 51-86, Fanon, F. (1983). Los condenados de la tierra. Fondo de Cultura Económica. Recuperado de http://www.rosa-blindada.info/b2img/FanonLoscondenadosdelatierra.pdf. Guattari, F. (2004). Plan sobre el planeta. Capitalismo mundial integrado y revoluciones moleculares. En colaboración con Gilles Deleuze. Madrid: Traficantes de sueños. $129 \mathrm{p}$.

Foucault, M. (l976). Vigilar y castigar. México: Fondo de Cultura Económica.

Habermas, J. (1993). Identidades nacionales y postnacionales. México: Rei.

Lander, E. Mignolo, W., Quijano, A. et ál. (200o). La colonialidad del saber, eurocentrismo y ciencias sociales. Buenos Aires, Argentina: CLACSO, febrero de 1993.

Mignolo, W. (2003). Historias locales/diseños globales. Colonialidad, conocimientos subalternos y pensamiento fronterizo. Madrid: Akal.

Mignolo, W., Walsk, C. et al. (2007). El giro decolonial. Reflexiones para una diversidad epistémica más allá del capitalismo global. Bogotá, Colombia: Siglo del Hombre Editores; Universidad Central, Instituto de Estudios Sociales Contemporáneos y Pontifi cia Universidad Javeriana, Instituto Pensar, 2007.

Walsh, C. (2005). Interculturalidad, colonialidad y educación. Bogotá, Colombia: Revista Educación y Pedagogía, Núm. 48 (2007), Universidad de Antioquia - Facultad de Educación. Recuperado de http://aprendeenlinea.udea.edu.co/revistas/index.php/revistaeyp/article/viewArticle/6652. Consultado en febrero 2015 .

Walsh, C. (2007). ¿Son posibles unas ciencias sociales/culturales otras? Reflexiones en torno a las epistemologías decoloniales. Revista Nómadas, (26), 102-113. 
